Introduction The mining sector that has driven the South African economy for over 100 years left a legacy of occupational lung diseases in mineworkers, their families and communities in Southern Africa not comparable with any other working populations and compounded by the migrant labour system. The 33000 mineworkers compensated for silicosis, 109000 for tuberculosis and 14000 for asbestos-related disease amongst other occupational lung diseases over the past 30 years is thought to be only the tip of the iceberg. This study aimed to document progress towards ameliorating this situation and identifying residual challenges.

Methods A review was conducted of relevant policy and legislation and epidemiological studies showing the size, shape and scope of occupational lung diseases and access of current and ex-mineworkers to prevention interventions, health services and compensation. This was supplemented by 12 semi-structured interviews and data analysis.

Result The approach to the occupational lung disease challenges within the Southern African mining sector included the development of a database of 600000 files, outreach services including fixed and mobile health units and financial services, tracking and tracing ex-mineworkers using geospatial mapping tools and increased compensation payments. Multi-stakeholder participation involving governments in the Southern Africa region, trade unions, the Chamber of Mines, ex-mineworker associations and multi-lateral agencies assisted with financial, infrastructural and technical resources.

Discussion The challenges in the post-apartheid era have meant that vast numbers of mineworkers who have fallen ill or became disabled as they worked to produce South Africa's mineral wealth were not receiving health services and compensation. Progress is now being made to address the problems identified. Despite these efforts there are barriers to access services including socio-cultural factors, distance and lack of knowledge amongst ex-mineworkers about occupational lung diseases and compensation.

\section{LIFE EXPECTANCY AT AN OPEN PIT COAL MINE IN COLOMBIA}

'Jaime Huertas, ${ }^{2} \mathrm{H}$ Piedrahita. ${ }^{1}$ PhD, Professor Universidad Nacional de Colombia; ${ }^{2}$ PhD, Occupational Health Division Head - Carbones del Cerrejón, Limited - Colombia

\subsection{6/oemed-2018-ICOHabstracts.717}

Introduction Several studies have shown that life expectancy of miners in underground mines is greatly reduced. The complex working conditions to which they are subjected and the associated social conditions explain this reduction. However, few studies have come forward to show whether life expectancy is also reduced in miners working in open pit mining. This study aims to determine the life expectancy of miners who have worked in an open pit coal mine in Colombia.

Methods 15153 people who worked at the Mine from 1982 to 2015 were included in the study: 6133 were active and 9040 had retired. The applied statistical methods estimate the survival function based on mortality tables and the KaplanMeier estimator. It also contains inference methods and an adjusted Cox regression model (1972) to determine some explanatory factors for mortality at La Mina.
Result Compared with the risk of dying by means of a logrank test among those who have worked in the mine against the risk of people from other parts in the country and from the area of influence of the mine, it has been found that they are significantly different ( $\mathrm{p}$-val $<0.001)$. The direction of this difference indicates that life expectancy for workers who have worked in this mine is greater than that of their zone of influence and that of the country.

Discussion The possible explanations for the higher life expectancy in these workers may be associated with the living conditions that they have access to due to high salary levels and the occupational control measures established in the company. The longevity characteristic of adult inhabitants of the region where this mine operates also contributes to higher life expectancy found in these workers.

\section{Musculoskeletal Disorders}

\section{MUSCULOSKELETAL DISORDERS AMONG NURSES: EPIDEMIOLOGICAL AND SEMI-QUANTITATIVE STUDY} 1,2 Lamia Bouzgarrou*, ${ }^{1,2,3}$ Amira Omrane, ${ }^{1,2}$ Irtyah Merchaoui, ${ }^{1}$ Selma Kammoun,
${ }^{1,2}$ Amine Daafa, ${ }^{4} \mathrm{Jacques}$ Malcahire, ${ }^{1,3} \mathrm{Neila}$ chaari. ${ }^{1}$ Department of Occupational Medicine
and Ergonomics, Faculty of Medicine of Monastir, Tunisia; ${ }^{2}$ Occupational Medicine
Department, Taher Sfar University Hospital, Mahdia, Tunisia; ${ }^{3}$ Occupational Medicine
Department Fattouma Bourguiba, University Hospital, Monastir; ${ }^{4}$ Hygiene and Work
Physiology Unit, Catholic University of Louvain, Brussels, Belgium

\subsection{6/oemed-2018-ICOHabstracts.718}

Introduction This study aimed to identify biomechanical risk factors of musculoskeletal disorders (MSD) among nurses.

Methods A cross sectional survey-structured by the Nordic MSDs questionnaire- was conducted through a representative sample of the 1179 paramedics providing nursing care in two university hospital in Tunisia $(n=301)$. A representative work period in each department was identified. A multidisciplinary working group, according to estimated usual physical load, divided theses departments into four homogeneous groups. Semi quantitative biomechanical constraints based on 56 direct observations with encoding software and over 2 hours each one was conducted, in accordance with the homogeneous exposure group sampling table. Physical load scores were elaborated according to the posture adopted, gestures performed and characteristic of handling (type, assistance, weight and autonomy of the patient) and assessed on the Chamoux physical strain scale.

Results The prevalence of the back MSDs was equal to $70.3 \%$. Variable prevalence of the upper limbs MSDs was noted according to the anatomical area $(43.68 \%$ for neck, $40.27 \%$ for shoulders, $15.01 \%$ for elbows and $29.35 \%$ for wrists).Observational study concluded that handling activity, as well as type and duration of constraining postures, were variable in function of the department of assignment. According to Chamoux scale the average physical load score was variable from 7.76 in departments with 'heavy physical requirement» to 7.25 in those associated to 'low' physical requirement. Multivariate analysis showed a significant difference concerning the thrust and the traction of light and heavy load, the activity of handling and the characteristics of the handled patients. It also concluded that paramedics affected to 
departments associated to heavier and less autonomous patient handling activity, were most affected by back MSD.

Discussion Our investigation identifies biomechanical risk factor of MSD among nurses and suggests the necessity of preventive actions according to exposure leve.

\section{NEWLY DEVELOPED AND REDESIGNED KEY INDICATOR METHODS FOR ASSESSMENT OF DIFFERENT PHYSICAL WORKLOADS - KEY ELEMENTS OF THE VALIDATION STUDY}

\footnotetext{
${ }^{1,2} \mathrm{~A}$ Klussmann*, ${ }^{3} \mathrm{~F}$ Liebers, ${ }^{3} \mathrm{~F}$ Brandstädt, ${ }^{3} \mathrm{M}$ Schust, ${ }^{1} \mathrm{P}$ Serafin, ${ }^{1} \mathrm{~A}$ Schäfer, ${ }^{1} \mathrm{H}$ Gebhardt, ${ }^{4} \mathrm{~B}$ Hartmann, ${ }^{3} \mathrm{U}$ Steinberg. 'Institute of Occupational Health, Safety and Ergonomics (ASER), Wuppertal, Germany; ' University of Wuppertal, Chair of Human Engineering, Wuppertal, Germany; ${ }^{3}$ Federal Institute for Occupational Safety and Health (BAuA), Berlin, Germany; ${ }^{4}$ ArbMedErgo Consultant, Hamburg, Germany
}

\subsection{6/oemed-2018-ICOHabstracts.719}

Introduction The assessment of work tasks with physical workloads is crucial to estimate the work-related health risks of employees. Three key indicator methods (KIMs) are available for risk assessment regarding manual lifting, holding and carrying of loads, manual pulling and pushing, and manual handling operations. Three further KIMs regarding whole-body forces, awkward body postures and body movement have been developed de novo. The development of a combined method for mixed exposures is planned. All methods will be validated regarding face validity, reliability, convergent validity, criterion validity.

Methods A mixed-methods study was designed for the validation of KIMs. The following working hypotheses (WH) are tested:

- WH 1: The KIMs reflect adequately the construct to be measured (face validity).

- WH 2: No relevant deviations occur between different users using KIMs and assessing the same workplaces (reliability).

- WH 3: Assessing workplaces using the KIMs and other screening methods will result in no relevant differences (convergent validity).

- WH 4: It is assumed that employees at workplaces with high KIM risk scores show adverse health related outcomes more frequently than non-exposed workers (criterion validity).

With this background a field study was conducted in companies of different sizes and branches in Germany as part of the joint project MEGAPHYS (multilevel risk assessment of physical workloads).

Ethics and dissemination: The study was planned and conducted in accordance with the Declaration of Helsinki, the design was approved by ethics committees. We intend to publish validated KIMs in 2018.

Acknowledgements/funding: The (further) development and validation of the KIMs is part of project MEGAPHYS funded by BAuA and the German Social Accident Insurance (DGUV). Further MEGAPHYS partners are Institute for Occupational Safety and Health of DGUV (IFA), Institute of Ergonomics at the Darmstadt University of Technology (IAD) and Leibniz Research Centre for Working Environment and Human Factors (IfADo).
1285 ASSOCIATION OF PSYCHOLOGICAL DISTRESS AND WORK-RELATED FACTORS AND MULTISITE MUSCULOSKELETAL PAIN AMONG TEACHERS IN MALAYSIA

${ }^{1,2}$ VC Hoe, ${ }^{1} \mathrm{FM}$ Moy, ${ }^{1} \mathrm{NN}$ Hairi, ${ }^{1} \mathrm{~S}$ Rampal, ${ }^{1} \mathrm{AM}$ Bulgiba. ${ }^{1}$ Centre for Occupational and Environmental Health-UM, Department of Social and Preventive Medicine, Faculty of Medicine, University of Malaya, Malaya, Malaya; ${ }^{2} J u l i u s$ Centre University of Malaya, Department of Social and Preventive Medicine, Faculty of Medicine, University of Malaya, Malaya, Malaysia

\subsection{6/oemed-2018-ICOHabstracts.720}

Introduction Work-related factors are known to be associated with musculoskeletal pain (MSP), however psychological distress may also play an important role. The study aims to evaluated the association between psychological distress and workrelated factors, and multisite MSP among teachers.

Methods This is a cross-sectional study conducted among teachers from six states in the Peninsular of Malaysia. Information on demographic characteristics, psychological distress, work-related factors and MSP from seven anatomical sites were collected using a self-administered questionnaire. Weight and height were measured using standardised methods. The association between MSP at three or more sites in the past month, and psychological distress and work-related factors were assessed using multivariate logistic regression.

Results 6796 teachers from 391 schools completed the questionnaire. The prevalence of self-reported MSP at three or more sites in past month were $38.22 \%$. The three most common sites were neck (42.15\%), shoulder (37.31\%) and feet (36.28\%). Psychological distress was more strongly associated with multisite MSP as compared to work-related factors, after controlling for potential confounders, i.e., age, gender, ethnicity, Body Mass Index, marital status and education level. Psychological distress symptoms like anxiety displayed the highest odds (Odds Ratio (OR) 2.27; 95\% Confidence Intervals (95\% CI) 1.97 to 2.63), followed with depression (OR 1.43; 95\% CI: 1.15 to 1.78 ) and stress (OR 1.35 ; 95\% CI: 1.03 to 1.76). The work-related factors with statistical significant findings were administrative duties $(<4 \mathrm{hr} /$ day) (OR 1.37; 95\% CI: 1.12 to 1.68 ), teaching ( $<15$ years) (OR 1.21; 95\% CI: 1.00 to 1.47$)$ and high psychological job demand (OR 1.05; 95\% CI: 1.04 to 1.07). Other work-related factors did not show any association.

Discussion The study found that psychological distress, i.e., anxiety, depression and stress have stronger association with multisite MSP. Intervention to reduce multisite MSP should include psychological distress along with the improving work processes.

\section{PREVALENCE OF MUSCULOSKELETAL DISEASES IN BANRO NAMOYA GOLD MINING WORKERS ATTENDING COMPANY CLINIC FROM JANUARY 2015 TO DECEMBER 2016}

${ }^{1}$ Onyimbo Kerama*, ${ }^{2}$ Kibor Kipkemoi Keitany. ${ }^{1}$ Chief Medical Officer, Banro Namoya Gold Mining, Democratic Republic of Congo; ${ }^{2}$ Occupational Health Practitioner, Department of Promotive and preventive health services, Ministry of Health, Kenya

10.1136/oemed-2018-ICOHabstracts.721 